\title{
Communicative Competence as the Priority in Professional Language Training
}

\author{
Sviatlana A.Dubinka ${ }^{1, *}$, Lizaveta A. Dubinka-Hushcha ${ }^{2, a}$ \\ ${ }^{1}$ Belarusian State University, Faculty of International Relations, Department of English for Economics, 220030, \\ Minsk, Republic of Belarus \\ ${ }^{2}$ Copenhagen Business School, Porcelænshaven 24B 4.53 2000, Frederiksberg Denmark \\ ${ }^{a}$ Email: dubinko@bsu.by \\ *Corresponding author. Email: svetlanadubinko@gmail.com
}

\begin{abstract}
Key provisions of the previous approaches to professional language training were mainly based on reproductive concepts of education, assimilating certain knowledge and skills. The priority in modern education lies on cognitively active methodology, which presupposes the development and disclosure of students' creative abilities as well as educational, professional and communicative competences. We consider the current issues of modern education within the context of the formation of social, cultural, emotional and collective intelligence. The increased cultural potential of a foreign language in the global world and the use of modern information and educational technologies in developing communicative competences help to solve the task of overcoming linguistic, ethnic and cultural barriers by preemptively predicting and smoothing over communication failures in business.
\end{abstract}

Keywords: communicative competence, social, cultural, emotional, collective intelligence, information and educational technologies

\section{INTRODUCTION}

The diversity of professional duties of a future specialist determines the multicomponent nature of his/her professional sphere which in recent years has become increasingly complex and multifaceted, where each area included in the composition has gotten its own thesaurus, interaction situations, a specific nomenclature of communicative and practical intentions as well as strategies for achieving them. Since the field of activity of future specialists develops and expands very dynamically, it is impossible to foresee and calculate all possible communicative general and professional situations. Therefore, the formation of language skills, general and specific speech skills on the basis of cognitive and socio-cultural, strategic competencies is of particular importance.

There have been intense studies in the field which have brought about ample information regarding the role of different competences in determining the level of language acquisition. The focus of this article is on the constituents of communicative competence in the professional profile of a future specialist in the context of intercultural communication, modern information and educational technologies contributing to their formation. The subject of this article is the process of enhancing students' communicative competence for effective business communication in a foreign language. The object of the study includes the constituents of effective business communication which comprise the professional profile of a future specialist. Teaching effective business communication requires taking into account such important components as: 1. a complex possession of a number of competencies that compose a professional profile of a modern specialist, which predetermines the goals and objectives of teaching a foreign language in a modern university; 2 . the combination of a personal approach with training in a team; 3. the development of students' social, cultural, emotional and collective intelligence; 4 . the formation of ability for intercommunication. The assumptions as to facilitating this process lie on efficacy of using modern information and educational technologies. 


\section{Professional COMMUNICATIVE COMPETENCE IN MODERN EDUCATIONL PROCESS}

A specialist who graduates from a modern university is expected to have a high level of social, general scientific, specialized knowledge, skills and abilities which, based on accumulated practical experience, will help him/her to successfully carry out active professional activities. All this is provided by fundamental scientific, methodological and practical training at the university. Then comes the process of continuous (more often autonomous) education: a specialist must be able to independently make professional decisions, take into account their social and economic consequences, continuously deepen own expertise, improve skills and abilities and stay updated about historical and modern trends of sustainable development.

According to the Educational Standard of Higher Education Majoring in World Economy in the Republic of Belarus, a specialist in world economy should develop the following competences during the course of studies: academic (including knowledge and skills in the educational disciplines studied, ability to learn), social and personal competencies (including cultural and value orientations, knowledge of moral values of society and the state, ability to follow them), professional competencies (including the ability to solve problems, develop plans and ensure their implementation in the chosen field of professional activity). Applied to learning a foreign language, the competences characterize a definite level of language acquisition, which help a future specialist to efficiently perform his/her duties in all spheres of professional activities. They include language (or linguistic), discourse, speech, communicative competences [1]. This list is supplemented by cultural, professional, strategic, social and other competences [2]. Thus, communicative competence is a wide concept which assumes various kinds of knowledge, social situations, differences in cultural values and beliefs, ethnical principles and standards [3].

Different approaches are mentioned by scientists as efficient in developing students' competences in the course of professional training. They depend on students' language level aimed at by the curriculum. Among them are Content and Language Integrated Learning (CLIL) and English as a Medium of Instruction (EMI) approaches [4] [5].

CLIL focuses on the interdisciplinary approach to training a future specialist: some disciplines or their separate units are taught in a foreign language. This method is characterized by a complex approach to the content of teaching and the language. Being widely used in modern educational systems of higher learning it is supplemented by additional objectives: "...cultural awareness, cognitive advantages, deeper content learning, internalization, self-confidence, motivation, learner autonomy, and others" [6]. The benefits of this approach are summarized in modern literature and expressed via four "C"s: content, cognition, communication, culture [7]. CLIL as a contentlanguage approach in their interdisciplinary combination means parallel teaching of a discipline and a foreign language, the latter being one of the aims of education.

With its spread in the spheres of business, science, technology English has acquired the status of a Lingua Franca (ELF), a language that is adopted as a common language between speakers whose native languages are different. Among the English speaking population only about $20 \%$ are native speakers of English [8]. Thus four persons of five use English as a foreign language, actually as ELF. The results of the research done in many spheres (including those published in journals with a high impact-factor) are presented in English. These factors contributed to the growing interest in learning English. Many universities invite native speakers to deliver lectures, give seminars (in pandemic conditions it has become even more prevalent due to various educational platforms).

The EMI approach has become widely spread. Unlike the CLIL method it suggests teaching a discipline or some of its sections in a foreign language. The latter becomes an instrument for learning the material of the disciplines studied. Within the framework of classes with the EMI approach students still have an opportunity to develop their perceptive and productive language skills, but the main objective of the educational process is acquiring professional knowledge and competence. Thus with the EMI approach in teaching the priority of competences is shifted to the professional communicative one. The spread of this method in the modern globalized world as a means of professional teaching has been determined by a variety of reasons and has been outlined in the current literature on the issues of modern educational trends [9]. The study of the application of the method has also allowed the authors of the articles published on the subject to outline some concerns of teachers and students. It is underlined that there is no empirical research into how much English students learn and how much content they absorb. Besides, it is noted that even students who speak good English have sometimes difficulty in coping with the material. Thus the professors teaching the EMI course had to cover less curriculum content [10]. Still with the students of high language proficiency and the curricula targeted on their further mastering communicative 
professional and language competencies the approach is highly demanded. In recent years due to agreements on cooperation with the universities and exchange programs the EMI approach is growing more and more popular especially within the master's courses. The question which arises in this context and which is highly disputed is the language status of teachers working with the EMI approach.

The dilemma 'to be or not to be' for native or near-native speakers participating in the EMI approach should be solved differently case by case depending on the language environment and professional orientation of the curriculum. The observations made by Professor Jennifer Jenkins, director of the Centre for Global Englishes at the University of Southampton and a prominent researcher in the field of English as a lingua franca, show that there are certain controversies to be taken into account. The global spread of English as a lingua franca in different spheres has brought about different Englishes. Non-native speaker's investment of time, energy and money in acquiring a 'native-like English' seems not much justified if there is no need or prospect for communicating with native speakers. According to the author the difference between English as a foreign language (EFL) and English as a lingua franca (ELF) is shown in their application in the modern world: English as a foreign language is used for communication with native speakers while English as a lingua franca is used as a language of intercultural communication [11].

Thus according to the tasks of intercultural business communication in developing communicative professional competence the EMI approach can be used with a variety of alternatives. Invited native speakers and original distant learning courses can solve part of the problem. Another alternative is the English language teachers who have obtained a second education in the professional area they taught English as a foreign language (EFL), and successful graduates from the university who have become recognized specialists in this sphere and have high language proficiency. The departments of the Faculty of International Relations have been working in this direction since 2015: a certain amount of academic hours is envisaged for lectures and seminars which are given by invited professors (not only native English speakers), educators within Fulbright English Teaching Assistantship Program as well as successful graduates from the faculty with a high language proficiency and practice (the latter is more the case for post graduate teaching).

Modern challenges of the global world put forward the tasks of interdisciplinary and integration approach to teaching students' communicative competence in business communication. A foreign language may be regarded as part of a process of parallel teaching a discipline and a foreign language on the one hand and as an instrument of professional training - on the other. Below you can see several principles of integration, on the basis of which departments of professional training and foreign languages develop various forms of educational, methodological, research and educational work.

The first principle is the integration of foreign language teaching and professional training. The second principle is the integration of professional knowledge into teaching a foreign language. These principles are actually the constituents of the concept of teaching the language of a specialty and teaching a specialty in a foreign language [12].

Thus, the most important pedagogical condition, optimal for the formation of competencies in the professional training of a future specialist is the interdisciplinary integration. It involves training the teaching staff and application of information technologies associated with the use of modern information technologies, a reasonable selection of professionally significant information material, the use of didactic tools, which helps to bring students' learning activities as close as possible to professional ones. The inseparable interaction of interpersonal and special communication in the professional sphere allows us to highlight the most important components of communicative competence in business communication in the international arena:

- the ability to generate and adequately interpret information in a foreign language, i.e. carry out textual activities;

- the ability to identify the conceptual system of the communication partner. This requires the knowledge of the socio-cultural characteristics of the partner which are reflected in the specifics of his structuring of business situations and his implementation of strategies and tactics as well as speech signals of interaction;

- the ability to identify the psychological features of the communicative behavior of representatives of the business community in a specific situation of professional interaction;

- the ability to build the communication process in accordance with the patterns and rules of speech communication.

Communicative competence here is based on the ability for verbal argumentation in the process of which the speakers state their position, express their attitude to the point of view of the interlocutor 
in the form of agreement, objection, doubt. They critically evaluate the information received, compare various facts and proposals and summarize the discussion. A characteristic feature of professional qualities and competence is that each of them is integrative in nature, because it combines many more narrow and specific indicators [13]. Thus, professional competence as a quality of a communicative personality is manifested in the readiness and ability of a specialist to carry out effective professional activities.

At the same time, professional knowledge is considered as a kind of basis, the foundation of a professional personality, and the skills and abilities that contribute to the formation of readiness to carry out this activity act as a superstructure in the scheme of professional competence. It is assumed that the portrait of a communicative personality in each professional area has its own distinctive features. Varying in the area of professional communication, these features can have much in common in the superstructure, since professional interaction can manifest an invariant character in the formation of interpersonal relations between representatives of different countries and cultures, since it is transmitted by generally accepted behavioral norms, as well as communicative rules and principles of sociocultural significance.

\section{INTERCULTURAL AWARENESS AND TYPES OF INTELLIGENCE IN EFFECTIVE BUSINESS COMMUNICATION}

Achievement of the goals and objectives in the context of the formation of competencies necessary for business communication is closely related to the formation of student's multicultural personality. Intercultural awareness includes the disclosure and understanding of one's own culturally determined behavior and thinking, as well as the cultural patterns of representatives of other cultures [14]. The process of intercultural awareness includes not only the perception of similarities and differences in other cultures, but also the recognition of the peculiarities of local culture or, as E. Hall notes, our own "hidden culture" [15]. Intercultural awareness is the force that moves the student through the continuity of acculturation from a state of misunderstanding or even hostility towards a new culture to almost complete understanding: from monoculturalism to bi- or multiculturalism. Of course, polar states are rarely observed. You cannot live and remain completely monocultural for a long time in the modern world. On the other hand, achieving a full state of acculturation is equally difficult.

Facilitating the journey through the continuous process of acculturation is of the utmost importance to the teacher. The final destination must be decided by the student. Many scientists recognize that successful communication requires a variety of outside intelligences (IQ), including emotional, cultural and social ones. The research in this area has shown that high emotional intelligence scores are some of the best predictors of success in international communication [16]. Daniel Goleman, analyzing different types of intelligence in business communication, expanded his research on emotional intelligence by including the study of social interaction, which, he says, combines two broad categories: social awareness (how we feel about others) and social medium (what we actually do then with this awareness) [17]. At the same time, social awareness includes four abilities: primary sympathy, attitude (the ability to listen with full receptivity), empathic accuracy (understanding the thoughts, feelings and intentions of another person) and social cognition (knowledge of how the social world works).

Social opportunities, on the other hand, are based on people's social awareness to conduct smooth, effective interactions and include a range of possibilities: synchronicity (smooth interaction at a non-verbal level), self-presentation (effective selfpresentation), influence (shaping the outcome of social interactions) and caring (caring for the needs of others)

Emotional intelligence includes all the skills needed to successfully understand and manage emotions - the non-cognitive psychological aspects that affect a person's behavior. Emotional intelligence includes the skills of self-awareness, self-management, understanding and managing relationships. It is also seen as an important construct for understanding and predicting behavior including the ability to effectively identify and perceive emotions in oneself and others, as well as skills in managing those emotions.

Cultural intelligence, on the other hand, can be defined as the ability of a person to adapt to a new cultural context, to manage people with different cultural backgrounds and understanding of cultural differences. Cultural intelligence is based on a larger area of individual difference, which consists of personality, abilities and interests, and is considered part of a person's ability. As with emotional and social intelligence, cultural intelligence does not give us any information about preferred kinds of behavior, but unlike these other forms of intelligence, it focuses on culturally significant abilities. It allows us to use the most appropriate behavior, including language, interpersonal skills or qualities such as ambiguity or flexibility, to adjust appropriately when interacting with people who have different cultural views and values. 
Cultural intelligence is also associated with emotional intelligence. The experience in managing people's emotions is determined by cultural values, beliefs and norms. Therefore, the process of evaluating, regulating and responding in intercultural situations can vary greatly in terms of the expression of behavior and its consequences in interactions between representatives of different cultures. In the context of intercultural competence, numerous skills need to be developed. Some of them have a clear practical focus, for example, communication and decision-making, and can be developed through active practice, increasing knowledge of the explicit and hidden aspects of these skills. Others can be based on developing habits that intercultural thinking cultivates, which in its turn influences behavior. Cultural skills also include the ability to differentiate between the ways that distinguish people and those that make people alike as well as understanding how individual differences and collective similarities interact. In teaching foreign language communication, in particular, foreign language professional communication, it is important to take into account the common and distinctive features in the value picture of the world of communication partners whether they are representatives of the same or different cultures.

The combination of individual (personal) and collective approach is another important component of effective communication. Recent technological advances in computing have led to the development of methods for measuring the intelligence of groups, according to which a group can demonstrate more knowledge than any individual, no matter how smart that individual is. This prompted Pierre Levy to use the term "collective intelligence" to describe a form of universal, distributed intelligence that arises from the collaboration and competition of many individuals. The work of P. Levy testifies to the continuous search for new opportunities for using human intelligence and developing it with the help of new technological tools. This is the problem of using knowledge that is not given to anyone in its entirety. Collective intelligence can be compared to a kind of interface, which, as active intelligence, according to P. Levy, embraces the entire human intelligence, arising from the bottom up out of the set of real human knowledge [18].

The concept of intelligence refers to the ability of the collective to solve problems, while at the individual level of knowledge it relates to the solution of problems [19]. These relationships are expected to persist at the collective level, so that the knowledge of each individual in the collective will contribute to problem-solving ability of the collective or collective intelligence. Collective intelligence is the next major phenomenon in information technology, focusing on things like "peopleware" and the "global brain." [20]. One area where the application of the tools and principles of collective intelligence is critical today is education. The teaching profession has traditionally involved participation in the development of curricula and lesson plans. More recently, this phenomenon of describing teachers as designers has generated a new interest, in part, due to the widespread availability of web resources [21].

Thus, the data obtained from recent studies on efficient business communication indicate that it is a highly specific process which includes the formation of different forms of intelligence which compose the professional portrait of a future specialist and the way they contribute to enhancing communication competence. The latter, in its turn, is composed of a variety of competences with the professional one being in the center.

\section{METHODOLOGY}

\section{A. Study area and sample selection}

The study was carried out at the Belarusian State University, Faculty of International Relations. A sample size of 53 respondents was selected purposively for this study among the students (parts $\mathrm{A}$ and $\mathrm{B}$ of the experiment). Postgraduate students were chosen for Part A of the experiment as both the CLIL and the EMI approaches were applied in their training. The fourth-year students participated in Part B of the experiment as it is their final year of studies at the university and we assume they have their own idea of a professional communicative portrait of a future specialist in the field of world economy.

\section{B. Questionnaire design and data collection}

The survey was conducted among the postgraduate students of the specialty "World economy" (Part A, 28 respondents) and the fourth-year students of the specialty "World economy"(Part B, 25 respondents). The response rate was $93,3 \%$, or 28 out of 30 people for Part A, 80, 3\% or 25 out of 30 people for Part B. The majority of the respondents participating in part $\mathrm{A}(82,3 \%)$ were 23 years old, $17,7 \%$ of the participants were 22 years old at the time of the survey. $92,3 \%$ of the respondents in Part B were 20 years old, 7,7\% were 21 years old. In the gender ratio, $87,4 \%$ of the respondents were women and 12,6\% - men in Part A. Part B was represented by $72,3 \%$ of women, $27,6 \%-$ men. The participation of the respondents was completely voluntary. The study employed a mixed-methods research design (quantitative - qualitative). A cross-sectional survey questionnaire method was used to collect the required data. Three sets of questionnaires were offered: one set for each part. Part A was aimed at 
evaluating advantages and disadvantages of the CLIL and EMI approaches for acquiring professional communicative competence. The respondents were also asked to give their recommendations, if they had any, how to increase the efficiency of this or that approach or eliminate the difficulties they experienced while studying ("Table I", questions 1, 2, 4). The aim of the survey in Part B was to compile a professional portrait of a specialist in the sphere of world economy. The questions were formulated with a view to assess the role of different types of competences and intelligence in professional training. The answers were chosen for the analysis according their predominance: those which had more than 50\% ("Table II"). The survey was conducted anonymously in the Google forms application. The data were collected using a questionnaire developed in English. The questionnaires were personally distributed by the researcher, and the respondents were made aware of their rights to withdraw their participation at any time during the study.

\section{Data analysis}

The results of the study were presented using descriptive statistics.

\section{RESULTS AND DISCUSSION}

\section{A. Part A}

It follows from the study that the CVIL approach overweighs in the possibility to improve language proficiency (72, 4\% of the respondents). Among the major EMI recommendations it is noted that less attention then desired is paid to language accuracy (lexis, grammar, phonetics). Among noticeable differences is point 4 - possibility to improve the skills of impromptu discussion on the professional topics in English: 76, 6\% respondents give preference to the EMI approach. They would like to be more immersed into the live professional atmosphere and situations. The possibility to improve the level of professional knowledge in English with the EMI approach is noted by 59, 2\% respondents. Questions 3 and 5 (Possibility to improve professional communication skills via free live communication and use of relevant foreign language materials showed the least difference among the approaches (48-52\% and 49,1-50,9\% respectively), shown in "Table I".

TABLE I. QUESTIONS FOR EVALUATING THE CLIL AND THE EMI APPROACH

\begin{tabular}{|c|c|c|}
\hline What positive issues can you note for learning world economy course with this approach? & CLIL advantages & EMI advantages \\
\hline 1. Possibility to improve the level of professional knowledge in English & $40,2 \% *$ & $59,8 \% * * *$ \\
\hline 2. Possibility to improve language proficiency & $72,40 \%$ & $27,6 \% * * * *$ \\
\hline 3. Possibility to improve professional communication skills via free live communication & $48 \%$ & $52 \%$ \\
\hline 4. Possibility to improve the skills of impromptu discussion on the professional topics in English & $23,4 \% * *$ & $76,60 \%$ \\
\hline 5. Use of relevant foreign language materials & $49,10 \%$ & $50,90 \%$ \\
\hline
\end{tabular}

${ }^{\text {a. }}$ CLIL recommendations: * to give an integrated course of all the topics and units; ** to be more immersed into the live professional atmosphere, situations

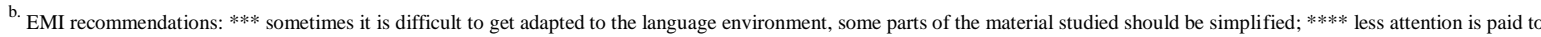
language accuracy (lexis, grammar, phonetics)

\section{B. Part B}

The points suggested in the survey were chosen to cover the major competences a future specialist of world economy should possess as well as the types of intelligence we consider most important: social, emotional, cultural and collective. The students were asked to choose among the four suggested variants of answer: "yes", "rather yes", "no". "rather no". According to the results obtained the answers were ranged according to the priority given to them: $100-90 \%$; 89-80\%; 79-70\%\%; 69$60 \% ; 59-50 \%$. Within the highest range we noted answers $1,2.3,6,8,9,10$ which reflect social, collective, emotional intelligence and professional communicative, sociocultural competences. The second range is represented by points $4,5,7,16$ with collective, cultural and emotional intelligence, professional and sociocultural competences. The third range includes points 14,15 , which show the attitude to cultural and social aspects. Range 4 shows point 11 (social and cultural aspects). Range
5 is represented by points $12,13,17$ (some social, collective and cultural aspects). All the aspects of intelligence attributed to the questions in the survey are connected with the professional area of training a future specialist. They are interconnected and contribute to the formation of professional communicative competence. The data of the survey show that the highest range (range 1) is represented by all "yes" answers. "No" and rather "no" answers are shown in ranges 3, 4, 5 ("Table II"). 
TABLE II. THE SURVEY FOR EVALUATING THE ROLE OF COMPETENCES IN THE PROFESSIONAL PORTRAIT OF A FUTURE SPECIALIST IN INTERNATIONAL RELATIONS (WORLD ECONOMY).

\begin{tabular}{|c|c|c|}
\hline 1. Possess verbal and written professional communication skills in a foreign language. & "yes" & $\mathbf{9 7 , 3 \%}$ \\
\hline 2. Have the ability for interpersonal communication & "yes" & $94,2 \%$ \\
\hline 3. Be able to work in a team. Back up the team & "yes" & $97,1 \%$ \\
\hline 4. Conduct commercial negotiations with foreign partners & "yes" & $\mathbf{8 3 , 5 \%}$ \\
\hline 5. Make decisions on your own & "yes" & $88,2 \%$ \\
\hline 6. Conduct sociocultural communication in a foreign language & "yes" & $\mathbf{9 7 , 3 \%}$ \\
\hline 7. Develop humour, tact, sensitivity & "rather yes" & $83,7 \%$ \\
\hline 8. Avoid conflicts & "yes" & $\mathbf{9 7 , 8 \%}$ \\
\hline 9. Show calm, patience and tolerance & "yes" & $\mathbf{9 8 , 3 \%}$ \\
\hline 10. Respect confidentiality and trust & "yes" & $93,7 \%$ \\
\hline 11. Clarify why people did and what they did & "no" & $62,4 \%$ \\
\hline 12. Promptness and punctuality are to be taken for granted & "yes" & $54,6 \%$ \\
\hline 13. Initiative is a welcome factor in business situations & "rather no" & $57,2 \%$ \\
\hline 14. Observe power distance in all business situations & "rather yes" & $72,2 \%$ \\
\hline 15. Eloquence guarantees success at business meetings & "no" & $\mathbf{7 4 , 2 \%}$ \\
\hline 16. Impressiveness of speech, argumentation & "rather yes" & $89,6 \%$ \\
\hline 17. Research activity & "rather no" & $52,4 \%$ \\
\hline
\end{tabular}

\section{DISCUSSION}

The study shows that a professional communicative portrait of a specialist in the field of world economy combines a number of professional, intercultural, linguistic, social competences which are linked with different aspects of intelligence: social, emotional, collective and cultural. They are marked as most important by the majority of respondents (more than 50\% of positive answers). Negative answers ("no" or "rather no") are given to points 11, 13, 15, 17. The question "Clarify why people did and what they did" shows the students' neutral versus emotional position and is more an issue of cultural dimension showing the principles of a linear culture they identify themselves with. "Initiative is a welcome factor in business situations" takes 57, $2 \%$ as a "rather no" answer (with $32,1 \%$ of "yes" answers and 10, 7\% of "no" answers).

It means that the students should be involved in productive activity during their training course to fully realize the importance of this factor in their professional career. This underlines the importance and the timeliness of the use of information and educational technologies in the systems of developmental, heuristic, and dialogue learning which are being introduced and are reflected in the curricula at the faculty with the focus on the creative self-realization of students, the development of their critical thinking and creative abilities, the creation of their own educational product.

"Eloquence guarantees success at business meetings" shows 74, $2 \%$ of "no" answers. It means that the students are well aware of the difference between impressiveness of speech, argumentation on the one hand (which give a positive effect and make an essential part of professional communicative training), and eloquence - on the other. The latter is rightly considered as a matter of cultural differences towards the perception of time and the adherence to the agenda of business meetings.

"Observe power distance in all business situations" receives $72,2 \%$ of "rather yes" answers. This high index of power distance lies in the sphere of cultural differences. It is therefore important while arranging business communication to explain to the students what other patterns they might deal with and how important it is to take into account the differences between them.

"Research activity" is presented by $52,4 \%$ of "rather no" answers. This indicator shows that a number of students have not chosen a scientific way of their professional career or rather don't identify their future profession with any kind of research. It means that a further educational strategy is needed to involve students in innovational and research activity and focus on its importance in their professional career.

\section{CONCLUSION}

Overall it may be concluded that in order to develop students' professional communicative competence we need to enhance a number of competences and develop different aspects of intelligence. The CLIL and the EMI approaches may be combined in solving this task: to immerse students into a professional language environment and give training in language accuracy and professional communication. An important role is played here by information and educational technologies in the systems of developmental, 
heuristic, and dialogue learning with the focus on the creative self-realization of students, the development of their critical thinking and creative abilities, the creation of their own educational product.

\section{References}

[1] A. N. Shchukin, "Linguodidactic Encyclopedic Dictionary". M.: ASTRAL: ACT: Khranitel, 2007, pp. 117-118.

[2] E. V. Voevoda, "The main directions of professionally oriented language training of an international specialist", MGOU, 2009, p.15.

[3] I. Klimova, G. Klimova, S. Dubinka, "Students's communicative Competence in the context of intercultural business communication". XLinguae 12(1), 2019, pp. 207218.

[4] D. Coyle, "Content and Language Integrated Learning", Cambridge: Cambridge University Press, 2010, 170p.

[5] Jenifer Jenkings, [Electronic resource]: University of Southampton. - Mode of access: https://www.southampton.ac/uk/ml/about/ataff/jj1a06.page \#teaching/ - Date of access: 06.02.2021.

[6] C. Dalton-Puffer, \& U. Smit, "Content and language integrated learning: A research agenda". Language Teaching, 46 (04), 2013, pp. 545-559.

[7] D, Lasagabaster, "Foreign language competence in content and language integrated courses". The Open Applied Linguistics Journal, 2008, 1(1), pp. 30-41.

[8] English as Lingua Franka (ELF): Where has EMI come from? [Electronic resource]: English as a Medium of Instruction for Academic Purposes, University of Southampton. - Mode of Access6 https://www.futurelearn.com/courses/emiacademics/5/steps/459135/. - Date of access: 06.02.2021.

[9] Jenifer Jenkings, op. cit.

[10] N. Galloway, "How effective is English as a medium of instruction (EMI)?" [Electronic resource] : https://www.britishcouncil.org/voices-magazine/howeffective-english-medium-instruction-emi - Date of access: 06.02 .20

[11] Jenifer Jenkings [Electronic resource]: An interview with an ELF researcher University of Southampton. - Mode of access:

https://www.elanguages.ac.uk/los/ma/an_interview_with_a n_elf_researcher.html - Date of access: 04.02.2021

[12] S. A. Dubinko, "Development of professionally significant competencies in teaching English to students of international economic profile, Practice of teaching foreign languages at the Faculty of International Relations of BSU: Minsk, 2017, pp. 60-61.

[13] T. V. Leontieva, "Development of professional competencies in the process of studying the discipline "music pedagogy", Naukovedenie, vol. 2, 2014. Mode of access: http://publ.naukovedenie.ru/- Date of access: 10.02.2021.

[14] Irina I. Klimova, Natalia E. Sharabarina, Elena A. Tikhova, Sviatlana A. Dubinka. "Communicative Competence Enhancement", XLinguae. Issue 1XL, January, 2018, pp. 67-74.

[15] E. T. Hall, "The Hidden Dimension”. Anchor Books 1969.
[16] R. Gabel-Shemueli, S. Dolan, "Do Emotions Matter?" Management Research. Vol. 9, № 3, 2011, pp. 207-229.

[17] D. P. Goleman, "Social Intelligence: New Science of Human Relationships". Amazon Books, 2006, p. 84.

[18] Lévy, P. "Collective intelligence: mankind's emerging world in cyberspace", Perseus Books, 1997, p. 262.

[19] K. Mchugh, F. Yammarino, S. Dionne, A. Serban, H. Sayama, \& S. Chatterjee. "Collective decision making, leadership, and collective intelligence: Tests with agentbased simulations and a Field study", The Leadership Quarterly. Vol. 27(2), 2016.

[20] L. A. Dubinka-Hushcha, "Augmenting collective intelligence through blended learning and open educational resources", Intercultural communication and professionally oriented teaching of foreign languages: Materials of the XIII International Scientific Conference dedicated to the 98th anniversary of the founding of the Belarusian State University, Minsk, 2019, pp. 105-108.

[21] E. A. Davis, K. Varma, "Supporting teachers in productive adaptation", Designing coherent science education: Implications for curriculum, instruction, and policy. New York, NY: Teachers College Press, 2008. 